Saudi Journal of Oral and Dental Research

Abbreviated Key Title: Saudi J Oral Dent Res ISSN 2518-1300 (Print) IISSN 2518-1297 (Online) Scholars Middle East Publishers, Dubai, United Arab Emirates Journal homepage: http://scholarsmepub.com/sjodr/

\title{
Knowledge and Attitute of Dental Practitioners of Karachi towards Usage of Endodontic Files: A Cross Sectional Study
}

Dr. Huma Sarwar, BDS, MDS ${ }^{1 *}$, Dr. Meshal M Naeem, BDS ${ }^{2}$, Dr. Hasan Afaq, MDS ${ }^{1}$, Dr. Sania Riaz, BDS ${ }^{3}$, Dr Sadia Farooqi, BDS ${ }^{4}$, Dr. Kiran Qamar, BDS ${ }^{4}$

${ }^{1}$ Lecturer Operative dentistry, DIKIOHS, DUHS

${ }^{2}$ MDS Trainee \& Lecturer Periodontology, DIKIOHS, DUHS

${ }^{3} \mathrm{Msc}$ Trainee \& Lecturer Periodonology, DIIOHS, DUHS

${ }^{4}$ Dental Officer, DIKIOHS, DUHS

DOI: $10.36348 /$ SJODR.2019.v04i10.010

| Received: 08.10.2019| Accepted: 14.10.2019| Published: 30.10.2019

*Corresponding author: Huma Sarwar

Abstract

Objective: The purpose of this study was to determine the current trends in usage, handling and dispensation of endodontic files by the dental practitioners of Karachi. Methodology: In this cross sectional study, two hundred and seventy survey performas were distributed to the dental teaching institutes and private dental clinics of Karachi. Survey participants were questioned about the preferred type of endodontic therapy, file system, method of dispensation of files, method of disinfection or sterilization of used files, criteria to discard used endodontic files and the preferred method of removal of debris from used files. SPSS version 21 was used for the calculation of frequency and percentage for statistical analysis. Results: Total two hundred and seventy survey forms were distributed out of which 200 were received with total response rate of $70.07 \% .45 .5 \%$ of dental practitioners perform manual root canal where as $19.5 \%$ prefer rotary endodontics. $82.25 \%$ respondents preferred to use Protaper files for rotary endodontics. $69.5 \%$ of the participants dipped the files in hydrogen peroxide while $20 \%$ kept their files in sodium hypochlorite while performing endodontic therapy. Autoclaving of the used files was found to be most common method amongst $87.5 \%$ of the participants and $80 \%$ of the respondents discard the files on first sign of deformation. $53 \%$ of the respondents dipped files in hydrogen peroxide to remove debris after usage. Conclusion: It was concluded that amongst the dental practitioners of Karachi, many follow the basic protocol to discard and reuse endodontic files. But majority of the practitioners keep endodontic files unnecessarily in agents not recommended for this purpose.

Keywords: Endodontic files, sterilization, file handling, rotary endodontics.

Copyright @ 2019: This is an open-access article distributed under the terms of the Creative Commons Attribution license which permits unrestricted use, distribution, and reproduction in any medium for non-commercial use (NonCommercial, or CC-BY-NC) provided the original author and source are credited.

\section{INTRODUCTION}

Root canal treatment is aimed at prevention or treatment of apical periodontitis. Prognosis of orthograde root canal treatment has been found to be as high as $95 \%$ for irreversible pulpitis and $85 \%$ for necrotic and infected pulp [1]. Root canal treatment requires the use of endodontic instruments for mechanical cleaning and shaping of the canals along the endodontic irrigation solutions [2]. These endodontic instruments; files, enlarge the root canal when used in apico-coronal direction of insertion and withdrawal from the root canal. Studies have highlighted the fact that use of rotary endodontic files has considerably reduced the procedural errors [3, 4]. Endodontic files are manufactured with mostly two different type of alloys; nickel titanium and stainless steel. Use of former alloys has been found to have higher resistance to torsional fracture whereas stainless-steel alloy instruments are relatively cheaper [5]. Endodontic file breakage is one dilemma that not only can lead to extreme stress for the clinician, but can cause great anxiety for the patient as well. Separated rotary nickeltitanium (NiTi) files can also pose an increased risk of post-endodontic complications. Reasons for endodontic instrument separation can be divided into patients or tooth related factors, operators expertise and mechanical properties of endodontic instruments. Many variables such as the operational speed, number of times files have been used, metal surface treatments and the metallurgic characterization of the endodontic files, that could possibly influence the fatigue resistance, have been investigated $[6,7]$. The endodontic files, even though for short duration, are in constant contact with endodontic irrigant during use and this short-term contact can cause significant detoriation on the surface of endodontic files $[9,10]$. The complex, miniature 
architecture of endodontic files makes the precleaning and sterilization difficult. Devising a sterilization protocol for endodontic files requires care. cleaning protocol for the removal of debris from endodontic files have been propsed by Parashos et al while performing endodontic therapy and before sterliaztion [11]. This national survey for a given region was conducted to determine the how well the evidence based guidelines have been followed by the dentists providing root canal treatment, in usage, sterilization and other aspects of handling of the endodontic files. Questionnaire based research studies for surveying the practices have been conducted in many countries [11-19]. The objective of this survey was to determine the current practices among dental practitioners of Karachi in endodontic file usage during and post-treatment phase.

\section{METHODOLOGY}

This cross sectional questionnaire-based study involved two hundred and seventy dental practitioners with different experience and academic background from different locations in Karachi. Verbal consent to participate in the study was obtained from all the participants after informing about the research context. Questionnaires were hand distributed and filled forms were retrieved at the same day. Study participants were asked about the preferred type of endodontic instrument, how many times a single set of endodontic file is used, criteria to reuse and discard of endodontic files. Data were collected and analyzed using SPSS version 21.0 and descriptive statistics and frequency and percentage were computed.

\section{RESULTS}

Total two hundred and seventy survey forms were distributed out of which two hundred were received with total response rate of $70.07 \%$. $66.5 \%$ dental practitioners had clinical experience of less than 5 years whereas $24.5 \%$ of dental practitioners had experience of more than 5 years of clinical practice. $88.5 \%$ of dentists worked in teaching hospitals where as $12.5 \%$ worked in private dental clinics. $45.5 \%$ of respondents preferred manual endodontics, $19.5 \%$ preferred rotary and $35 \%$ participants preferred both at their dental practice (Table-1). Protaper Universal file system was found to be the most popular endodontic rotary file system among the respondents $(82.5 \%)$ as shown in Table-2. Preferred method for dispensation of files during treatment was also inquired and majority of the research participants $(69.5 \%)$ chose to keep endodontic files immersed in dappen dish containing hydrogen peroxide during endodontic therapy whereas $20 \%$ preferred keeping files dipped in sodium hypochlorite. $4.5 \% \mathrm{kept}$ in saline and $5 \%$ of the participants preferred to keep their file dry in endodontic sponges (Table-3). Table-4 shows that majority of the dental clinicians $(87.5 \%)$ preferred to reuse the endodontic files after being autoclaved, $4.5 \%$ preferred cold sterilization, $2.5 \%$ use glass beads sterilization. $80 \%$ respondents discard endodontic files at the first visible sign of deformation (Table-5). Table 6 shows that majority of the participants (53\%) preferred to remove gross debris from the endodontic files by dipping in dappen dish containing hydrogen peroxide.

Table-1: Distribution of preferred type of endodontic therapy

\begin{tabular}{|l|l|l|l|l|l|l|}
\hline & \multicolumn{3}{|c|}{ Qualification } & Frequency & Percentage \\
\hline & House officers & PG Residents & Endodontists & General dentist & & \\
\hline Manual & 33 & 15 & 26 & 17 & 91 & $45.5 \%$ \\
\hline Rotary & 1 & 9 & 10 & 19 & 39 & $19.5 \%$ \\
\hline Both & 16 & 26 & 14 & 14 & 70 & $35 \%$ \\
\hline
\end{tabular}

Table-2: Distribution of preferred type of rotary instruments

\begin{tabular}{|l|l|l|l|l|l|c|}
\hline & \multicolumn{4}{|c|}{ Qualification } & Frequency & Percentage \\
\hline & House officers & PG Residents & Endodontists & General dentist & & \\
\hline Protaper & 45 & 44 & 35 & 41 & 165 & $82.5 \%$ \\
\hline Race & 0 & 0 & 1 & 0 & 1 & $0.5 \%$ \\
\hline shape one & 2 & 2 & 3 & 2 & 9 & $4.5 \%$ \\
\hline wave one & 1 & 0 & 0 & 1 & 2 & $1 \%$ \\
\hline Other & 0 & 3 & 2 & 2 & 7 & $3.5 \%$ \\
\hline
\end{tabular}

Table-3: Distribution of preferred method of files dispensation during endodontic therapy

\begin{tabular}{|c|c|c|c|c|c|c|}
\hline & \multicolumn{4}{|c|}{ Qualification } & Frequency & Percentage \\
\hline & $\begin{array}{l}\text { House } \\
\text { officers }\end{array}$ & $\begin{array}{l}\text { PG } \\
\text { Residents }\end{array}$ & Endodontists & $\begin{array}{l}\text { General } \\
\text { dentist }\end{array}$ & & \\
\hline files are kept dry & 2 & 4 & 3 & 1 & 10 & $5 \%$ \\
\hline $\begin{array}{l}\text { dipped in hydrogen } \\
\text { peroxide }\end{array}$ & 32 & 37 & 30 & 40 & 139 & $69.5 \%$ \\
\hline $\begin{array}{l}\text { dipped in sodium } \\
\text { hypochlorite }\end{array}$ & 15 & 5 & 12 & 8 & 40 & $20 \%$ \\
\hline dipped in saline & 1 & 3 & 4 & 1 & 9 & $4.5 \%$ \\
\hline
\end{tabular}


Huma Sarwar et al; Saudi J Oral Dent Res, Oct 2019; 4(10): 747-750

Table-4: Distribution of preferred method of files disinfection/sterilization

\begin{tabular}{|c|c|c|c|c|c|c|}
\hline & \multicolumn{4}{|c|}{ Qualification } & Frequency & Percentage \\
\hline & House officers & PG Residents & Endodontists & General dentist & & \\
\hline i dont reuse files & 2 & 2 & 2 & 2 & 8 & $4 \%$ \\
\hline cold sterilization & 2 & 5 & 1 & 1 & 9 & $4.5 \%$ \\
\hline autoclaving & 42 & 41 & 47 & 45 & 175 & $87.5 \%$ \\
\hline glass bead & 3 & 1 & 0 & 1 & 5 & $2.5 \%$ \\
\hline Disinfect & 1 & 0 & 0 & 1 & 2 & $1 \%$ \\
\hline
\end{tabular}

Table-5: Distribution of criteria chosen to discard used endodontic files

\begin{tabular}{|l|l|l|l|l|l|l|}
\hline & \multicolumn{3}{|c|}{ Qualification } & Frequency & Percentage \\
\hline & $\begin{array}{l}\text { House } \\
\text { officers }\end{array}$ & $\begin{array}{l}\text { PG } \\
\text { Residents }\end{array}$ & Endodontists & $\begin{array}{l}\text { General } \\
\text { dentist }\end{array}$ & & \\
\hline $\begin{array}{l}\text { i use new set of files for } \\
\text { every tooth }\end{array}$ & 2 & 2 & 2 & 2 & 8 & $4 \%$ \\
\hline after file breakage & 10 & 4 & 3 & 1 & 18 & $9 \%$ \\
\hline $\begin{array}{l}\text { at first sign of deformation } \\
\text { (unwinding) }\end{array}$ & 36 & 37 & 41 & 46 & 160 & $80 \%$ \\
\hline when used in multiple canals & 2 & 4 & 7 & 1 & 14 & $7 \%$ \\
\hline
\end{tabular}

Table-6: Distribution of preferred method for removal of gross debris from endodontic files

\begin{tabular}{|c|c|c|c|c|c|c|}
\hline 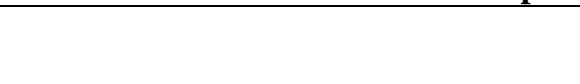 & $\begin{array}{l}\text { House } \\
\text { officers }\end{array}$ & $\begin{array}{l}\text { PG } \\
\text { Residents }\end{array}$ & Endodontists & $\begin{array}{l}\text { General } \\
\text { dentist }\end{array}$ & & \\
\hline moist cotton with saline & 3 & 5 & 18 & 13 & 39 & $19.5 \%$ \\
\hline moist cotton with $\mathrm{NaOCl}$ & 3 & 8 & 5 & 5 & 21 & $10.5 \%$ \\
\hline $\begin{array}{l}\text { keep files in dippen dish containing } \\
\text { hydrogen peroxide }\end{array}$ & 34 & 27 & 20 & 25 & 106 & $53 \%$ \\
\hline $\begin{array}{l}\text { keep files in dippen dish containing } \\
\mathrm{NaOCl}\end{array}$ & 10 & 6 & 6 & 7 & 29 & $11.5 \%$ \\
\hline flush with water & 0 & 4 & 1 & 0 & 5 & $2.5 \%$ \\
\hline
\end{tabular}

\section{DISCUSSION}

According to the results of the present study, majority of the fresh graduates (house officers) preferred manual endodontics but among endodontists rotary instrumentation was preferred. These findings are similar to a study conducted in India [13], khatmandu [14], Iran [15] and UK [16] in which rotary endodontics was chosen by most of the endodontists. A survey conducted in US concluded that majority of the fresh graduates preferred rotary endodontics contradicting the results of the present study in which majority of the house officers preferred manual instrumentation to perform endodontics [17]. In present study, Protaper Universal file system was most preferred type of rotary file system amongst dental practitioners. These results are similar to another study conducted by Petel et al., [13] whereas different than a study conducted amongst French dental practitioners [18]. According to a study conducted by Arun et al., [12] only 7\% practitioners use chemicals to remove gross debris from the endodontic files where as in present study, most of the dental practitioners preferred chemicals like hydrogen peroxide for the removal of gross debris from the endodontic files but none had mentioned use of the $0.2 \%$ chlorhexidine, the suggested protocol for disinfection of files. An endodontic file laden with organic biological debris can lead to reduction in the treatment outcome. Previously conducted studies on disinfection of the endodontic files [12, 14, 17, 19, 20], none has suggested dipping in hydrogen peroxide as opposed to the common practice found among dental practitioners in this research which is quite alarming. In the present study, it was found that most of the dental practitioners prefer to reuse endodontic files after autoclaving. Similar results were observed in a number of studies conducted previously [12, 14, 17, 19, 20]. According to a study conducted in UK, $44 \%$ of the dental practitioners prefer single use of endodontic instruments contradicting the results of the present study [16]. Whereas a Korean study concluded that most of the practitioners discard their endodontic files after using in 10 canals [21]. Most of the dental practitioners in the present study preferred to discard endodontic files when visible signs of deformation were seen on the instruments. These results are corroborating with the results of the previous studies [13, 22]. A study compared techniques of cleaning endodontic files after use concluded sponge with alcohol was least effective whereas gauze alcohol and ultrasonic bath were found to be equally effective both none of these methods completely cleaned the files of biological debris [23].

\section{CONCLUSION}

It can be concluded from the results of the present studies that basic protocol to discard and re-use endodontic instruments is practiced by majority of the 
Huma Sarwar et al; Saudi J Oral Dent Res, Oct 2019; 4(10): 747-750

dental clinicians of Karacahi. However, many practitioners keep endodontic instruments unnecessarily in agents not recommended for this purpose.

\section{REFERENCES}

1. Chugal, N. M., Clive, J. M., \& Spångberg, L. S. (2003). Endodontic infection: some biologic and treatment factors associated with outcome. Oral Surgery, Oral Medicine, Oral Pathology, Oral Radiology, and Endodontology, 96(1), 81-90.

2. Zehnder, M. (2006). Root canal irrigants. Journal of endodontics, 32(5), 389-398.

3. Cheung, G. S., \& Liu, C. S. (2009). A retrospective study of endodontic treatment outcome between nickel-titanium rotary and stainless steel hand filing techniques. Journal of endodontics, 35(7), 938-943.

4. Peters, O. A., Barbakow, F., \& Peters, C. I. (2004). An analysis of endodontic treatment with three nickel-titanium rotary root canal preparation techniques. International

Journal, 37(12), 849-859.

5. Walia, H., Brantley, W. A., \& Gerstein, H. (1988). An initial investigation of the bending and torsional properties of Nitinol root canal files. Journal of endodontics, 14(7), 346-351.

6. Padavala, S., \& Ganapathy, D. (2019). Fatigue in rotary endodontic instruments-A review. Drug Invention Today, 11(3).

7. Shen, Y., Coil, J. M., Mclean, A. G., Hemerling, D. L., \& Haapasalo, M. (2009). Defects in nickeltitanium instruments after clinical use. Part 5: single use from endodontic specialty practices. Journal of endodontics, 35(10), 13631367.

8. Gambarini, G., Grande, N. M., Plotino, G., Somma, F., Garala, M., De Luca, M., \& Testarelli, L. (2008). Fatigue resistance of engine-driven rotary nickel-titanium instruments produced by new manufacturing methods. Journal of endodontics, 34(8), 1003-1005.

9. Prasad, P. S., Sam, J. E., \& Arvind Kumar, K. (2014). The effect of 5\% sodium hypochlorite, $17 \%$ EDTA and triphala on two different rotary Ni-Ti instruments: An AFM and EDS analysis. Journal of conservative dentistry: $J C D, 17(5), 462$.

10. Berutti, E., Angelini, E., Rigolone, M., Migliaretti, G., \& Pasqualini, D. (2006). Influence of sodium hypochlorite on fracture properties and corrosion of ProTaper Rotary instruments. International endodontic journal, 39(9), 693-699.

11. Parashos, P., Linsuwanont, P., \& Messer, H. H. (2004). A cleaning protocol for rotary nickeltitanium endodontic instruments. Australian dental journal, 49(1), 20-27.

12. Aslam, A., Panuganti, V., Nanjundasetty, J. K., Halappa, M., \& Krishna, V. H. (2014). Knowledge and attitude of endodontic postgraduate students toward sterilization of endodontic files: a crosssectional study. Saudi Endodontic Journal,4(1), 18.

13. Patil, T. N., Saraf, P. A., Penukonda, R., VANAkI, S. S., \& Kamatagi, L. (2017). A survey on nickel titanium rotary instruments and their usage techniques by endodontists in India. Journal of Clinical and Diagnostic Research: JCDR, 11(5), ZC29.

14. Shrestha, D., Dahal, M., \& Karki, S. (2013). An endodontic practice profile amongst general dental practitioners in Kathmandu: A questionnaire survey. Journal of College of Medical SciencesNepal, 9(4), 40-50.

15. Mozayeni, M. A., Golshah, A., \& Kerdar, N. N. (2011). A survey on NiTi rotary instruments usage by endodontists and general dentist in Tehran. Iranian endodontic journal, 6(4), 168.

16. Madarati, A. A., Watts, D. C., \& Qualtrough, A. J. E. (2008). Opinions and attitudes of endodontists and general dental practitioners in the UK towards the intracanal fracture of endodontic instruments: part 1. International endodontic journal,41(8), 693-701.

17. Bird, D. C., Chambers, D., \& Peters, O. A. (2009). Usage parameters of nickel-titanium rotary instruments: a survey of endodontists in the United States. Journal of endodontics, 35(9), 1193-1197.

18. Arbab-Chirani, R., \& Vulcain, J. M. (2004). Undergraduate teaching and clinical use of rotary nickel-titanium endodontic instruments: a survey of French dental schools. International endodontic journal, 37(5), 320-324.

19. Kubde, R., Shenoi, P., Ghosh, S., Heda, D., \& Makade, C. (2019). Endodontic Instrument Sterilization'practices \& Monitoring In Private Dental Clinics. International Journal of Scientific Research, 8(5).

20. Perakaki, K., Mellor, A. C., \& Qualtrough, A. J. E. (2007). Comparison of an ultrasonic cleaner and a washer disinfector in the cleaning of endodontic files. Journal of Hospital Infection, 67(4), 355359.

21. Lee, W., Song, M., Kim, E., Lee, H., \& Kim, H. C. (2012). A survey of experience-based preference of Nickel-Titanium rotary files and incidence of fracture among general dentists. Restorative dentistry \& endodontics, 37(4), 201-206.

22. Parashos, P., \& Messer, H. H. (2004). Questionnaire survey on the use of rotary nickeltitanium endodontic instruments by Australian dentists. International endodontic journal, 37(4), 249-259.

23. Murgel, C. A. F., Walton, R. E., Rittman, B., \& Pécora, J. D. (1990). A comparison of techniques for cleaning endodontic files after usage: a quantitative scanning electron microscopic study. Journal of endodontics, 16(5), 214-217. 